\title{
Formation of Silicon Nanowires by CVD Using Gold Catalysts at Low Temperatures
}

\author{
Hiroshi Suzuki, Hiroshi Araki, Masahiro Tosa and Tetsuji Noda \\ National Institute for Materials Science, Tsukuba, 305-0047, Japan
}

Silicon nanowires (SiNWs) on a $\{100\}$ silicon wafer coated with a gold film were formed by thermal cracking of disilane at $473-573 \mathrm{~K}$. The SiNWs were single-crystalline with $10-100 \mathrm{~nm}$ in diameter and a $\langle 111\rangle$ crystal orientation. The optimum conditions for obtaining long SiNWs that are several hundred $\mu \mathrm{m}$ long include a disilane flow rate of $0.017 \mathrm{~cm}^{3} / \mathrm{s}$, an argon gas flow rate of $0.33 \mathrm{~cm}^{3} / \mathrm{s}$, and a total pressure of $0.67 \mathrm{kPa}$. The low-temperature formation of SiNWs was explained by lowering the melting point of Au-Si eutectic particles. Self-wiring of SiNWs between gold square dots placed $15 \mu \mathrm{m}$ from each other was successfully conducted. [doi:10.2320/matertrans.MRA2007059]

(Received March 8, 2007; Accepted May 23, 2007; Published July 19, 2007)

Keywords: silicon, nanowire, chemical vapor deposition processes, disilane, wiring

\section{Introduction}

One-dimensional nanowires are receiving attention from the viewpoint of their application to micro-sized devices as well as their physical and chemical properties, which differ from those of bulk materials. Silicon nanowires (SiNWs) are considered attractive for micro-electronics, ${ }^{1-4)}$ optoelectronics, ${ }^{5,6)}$ micro-chemical sensors, ${ }^{1)}$ and micro-component devices ${ }^{7)}$ due to their quantum confinement effects and peculiar structures with a high aspect ratio in nanosize. SiNWs have been formed using various methods, such as laser ablation, ${ }^{8)}$ thermal evaporation, ${ }^{9,10)}$ solid reaction, ${ }^{11)}$ and chemical vapor deposition (CVD). ${ }^{12-14)}$ In order to apply SiNWs to microelectronics, several efforts to control the size, growth, and direction at a specified place have been made., ${ }^{4,5}, 15$-17) Another important issue regarding the application of SiNWs to electronics devices is how the nanowires are formed at low temperatures so that the circuits are not damaged by heating. SiNWs have been thus tried to grow at low temperatures by utilizing metal catalysts, such as gold, ${ }^{2,5)}$ nickel, ${ }^{3,4)}$ and iron, ${ }^{8,9)}$ whose alloys with silicon have low eutectic temperatures. Recently, nickel silicide wires were synthesized at $593 \mathrm{~K}$ using silane gas. ${ }^{4)}$ However, the synthesis of SiNWs at further lower temperatures is necessary so that even noncrystalline substrates, such as plastics and glass, can be utilized in electronic devices. ${ }^{18)}$ Regarding the wiring of nanowires for certain devices, several efforts to form nanowires directly on specific structures have been made for SiNWs, ${ }^{15)}$ nickel silicide wire, ${ }^{4)}$ and carbon nanotubes, ${ }^{19)}$ among others. For the wiring of SiNWs, SiNWs bridges were formed between two vertical silicon sidewalls at a distance of $2-15 \mu \mathrm{m} .{ }^{15)}$ However, the formation of SiNWs on the designed patterns must be controlled for realizing nanowire devices.

In the present study, the synthesis and self-wiring of SiNWs between arrayed gold particles using disilane decomposition by CVD below $573 \mathrm{~K}$ were attempted.

\section{Experimental Procedures}

\subsection{Preparation of materials}

Silicon nanowires were grown on $4 \mathrm{~mm} \times 5 \mathrm{~mm} \times 0.5 \mathrm{~mm}$
$\{100\}$ silicon wafers coated with gold and $\{100\}$ silicon-on insulator wafers (SOI wafers). The structure of an SOI wafer is made up of a silicon layer bonded on an oxidized silicon single-crystal wafer. SOI wafers with silicon square dots ( $3 \mu \mathrm{m}$ square by $2 \mu \mathrm{m}$ high) placed at $15 \mu \mathrm{m}$ intervals on a $2 \mu$ m-thick $\mathrm{SiO}_{2}$ layer were obtained from NTT-AT Co. The top surface of the dots was then covered with gold of approximately $2 \mathrm{~nm}$ thickness by sputtering. The gold and $\mathrm{SiO}_{2}$ layers on the silicon surface, but not the dots, were removed by etching in a $0.1 \mathrm{M} \mathrm{KOH}$ solution. The schematic silicon dot pattern is shown in Fig. 1. The substrates with gold dots were mainly used for the wiring experiments of SiNWs. Another rectangular substrate of a $\{100\}$ silicon wafer ( $5 \mathrm{~mm}$ in length and $0.5 \mathrm{~mm}$ in width) covered with ca. $2 \mathrm{~nm}$-thick gold film was also prepared to optimize the growth conditions of SiNWs. That substrate had a single $15 \mu \mathrm{m}$-wide groove in the center of the sample; thus, it was confirmed that SiNWs had bridged the groove. The substrate

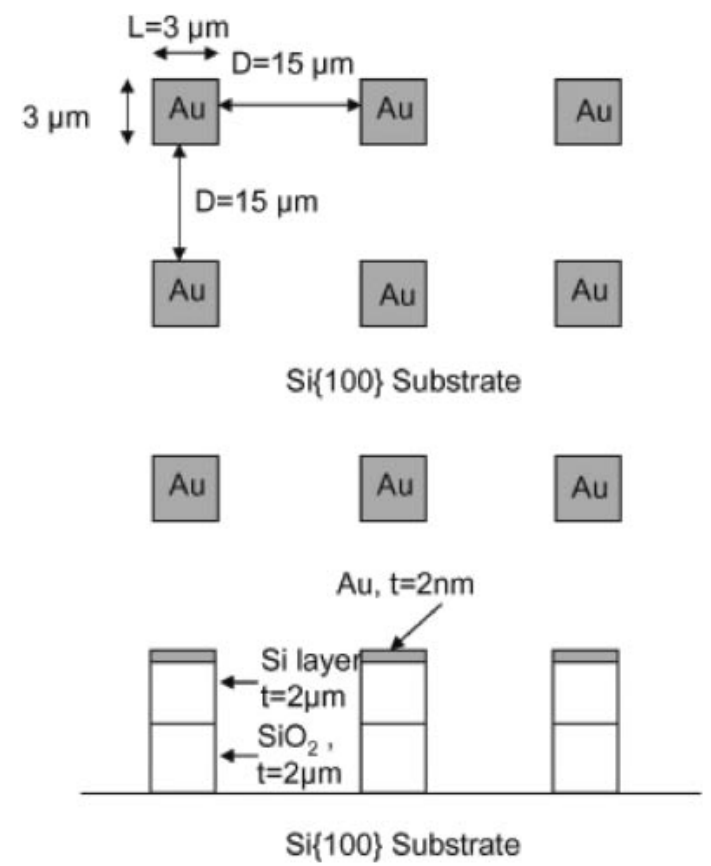

Fig. 1 Schematic diagram of a gold-dot pattern on a silicon substrate. 


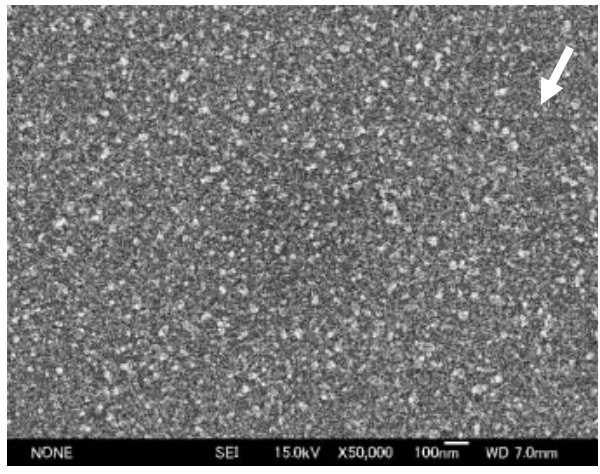

(a) $\mathrm{T}=423 \mathrm{~K}$

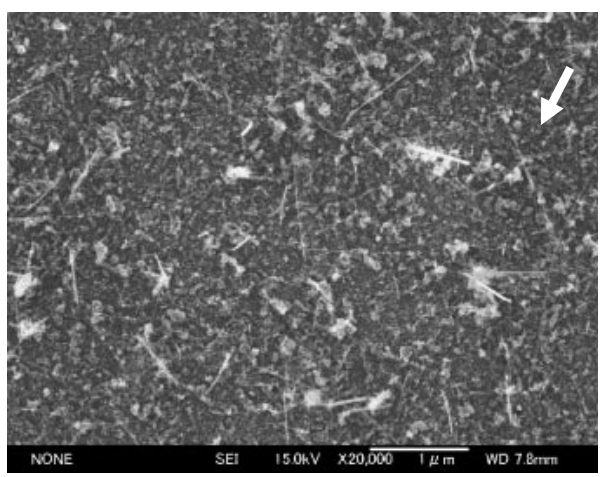

(c) $\mathrm{T}=473 \mathrm{~K}$

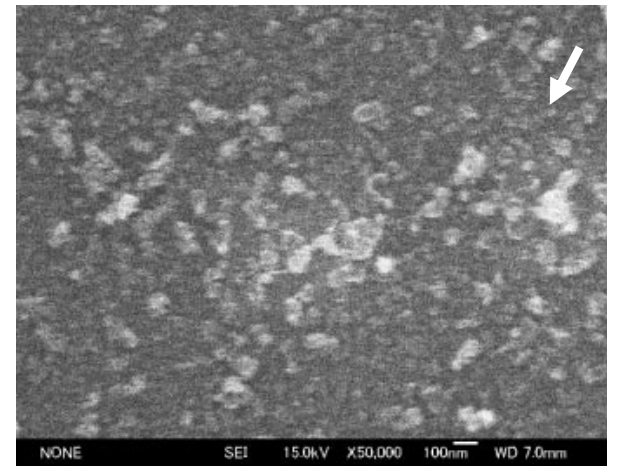

(b) $\mathrm{T}=453 \mathrm{~K}$

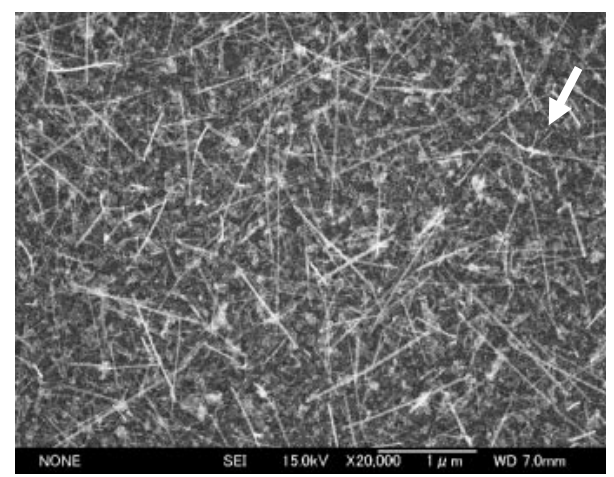

(d) $\mathrm{T}=523 \mathrm{~K}$

Fig. 2 Effect of the temperature on the morphology of silicon deposition. The flow rates of disilane and argon gases and the total pressure are $0.017 \mathrm{~cm}^{3} / \mathrm{s}, 0.33 \mathrm{~cm}^{3} / \mathrm{s}$, and $0.67 \mathrm{kPa}$, respectively. The arrows indicate the gas flow directions.

was placed into a stainless tube inside a vacuum chamber so that the flow of reactant gas could be controlled. After evacuating the chamber up to $1 \times 10^{-5} \mathrm{~Pa}$, the substrate was heated at fixed temperatures. A $10 \% \mathrm{Si}_{2} \mathrm{H}_{6}$ gas diluted with $\mathrm{H}_{2}$ and argon gas were then introduced into the chamber. The disilane and argon gases were run at constant rates ranging from 0.0083 to $0.033 \mathrm{~cm}^{3} / \mathrm{s}$ and 0.33 to $1.7 \mathrm{~cm}^{3} / \mathrm{s}$, respectively. The total pressure was set at $0.013-0.67 \mathrm{kPa}$. The temperature of the samples was kept at $423-573 \mathrm{~K}$ for 300 $1200 \mathrm{~s}$. After heating, the samples were examined with SEM, EDS, and TEM.

\section{Results}

\subsection{SiNW formation}

SiNWs were formed on a silicon wafer coated with gold by changing the temperature of the substrate as well as the flow rates and pressure of the reactant and dilution gases to determine the optimum formation condition. The effect of the temperature on the formation of SiNWs is shown in Fig. 2. In these figures, the flow rates of $\mathrm{Si}_{2} \mathrm{H}_{6}$ and $\mathrm{Ar}$ are controlled at $0.017 \mathrm{~cm}^{3} / \mathrm{s}$ and $0.33 \mathrm{~cm}^{3} / \mathrm{s}$, respectively, and the total pressure is set at $0.67 \mathrm{kPa}$. The heating time is $300 \mathrm{~s}$. Silicon particle deposition occurred on the gold surface at $423 \mathrm{~K}$. Clear SiNWs were grown at $473 \mathrm{~K}$. The length of SiNWs decreased with decreasing the total pressure. In Fig. 2, the gas flow directions are indicated by arrows. The relationship between the growth direction and the flow direction is not clear for the heating time of $300 \mathrm{~s}$ at any temperature.

Figure 3 shows the effect of the Ar flow rate on the morphology of the growth of SiNWs near the groove. Heating was conducted for $1200 \mathrm{~s}$ at $573 \mathrm{~K}$ with Ar flow rates of $1.7 \mathrm{~cm}^{3} / \mathrm{s}$ (Fig. 3(a)) and $0.33 \mathrm{~cm}^{3} / \mathrm{s}$ (Fig. 3(b)). The flow rate of $\mathrm{Si}_{2} \mathrm{H}_{6}$ and the total pressure were the same as those in Fig. 2. The SiNWs tended to get longer at lower flow rates of $\mathrm{Ar}$, as seen in Fig. 3(b). At $1.7 \mathrm{~cm}^{3} / \mathrm{s}$, the nanowires grew straightforwardly, but they were short. On the other hand, the nanowires at $0.33 \mathrm{~cm}^{3} / \mathrm{s}$ reached the other side of the edge of the groove, and several nanowire bridges were formed, as seen in Fig. 3. The growth direction of SiNWs tended to become parallel to the flowing direction of the reactant gas with the growth of nanowires. The optimum flow rates and pressure conditions for the growth of longer silicon nanowires were $0.017 \mathrm{~cm}^{3} / \mathrm{s}$ of $\mathrm{Si}_{2} \mathrm{H}_{6}, 0.33 \mathrm{~cm}^{3} / \mathrm{s}$ of $\mathrm{Ar}$, and $0.67 \mathrm{kPa}$ of the total pressure at $473 \mathrm{~K}-573 \mathrm{~K}$ in the present experimental system. The diameter and length of the nanowires ranged from 10 to $100 \mathrm{~nm}$ and from around $10 \mu \mathrm{m}$ to several hundred $\mu \mathrm{m}$, respectively. The typical microstructure of SiNWs analyzed by TEM is shown in Fig. 4. The SiNWs were formed for $300 \mathrm{~s}$ at $523 \mathrm{~K}$ under the above optimum gas flow and total pressure conditions. The SiNWs shown in Fig. 4(a) are almost single crystals with a $\{110\}$ surface and grew in a $\langle 111\rangle$ direction. As is already described, gold particles on the substrate play the role of catalysts in the growth of SiNWs. In Fig. 4(b), silicon nanowires with a gold particle on the top are clearly observed.

\subsection{Wiring of SiNWs}

The self-wiring of silicon nanowires between dots was attempted under the optimum experimental conditions 


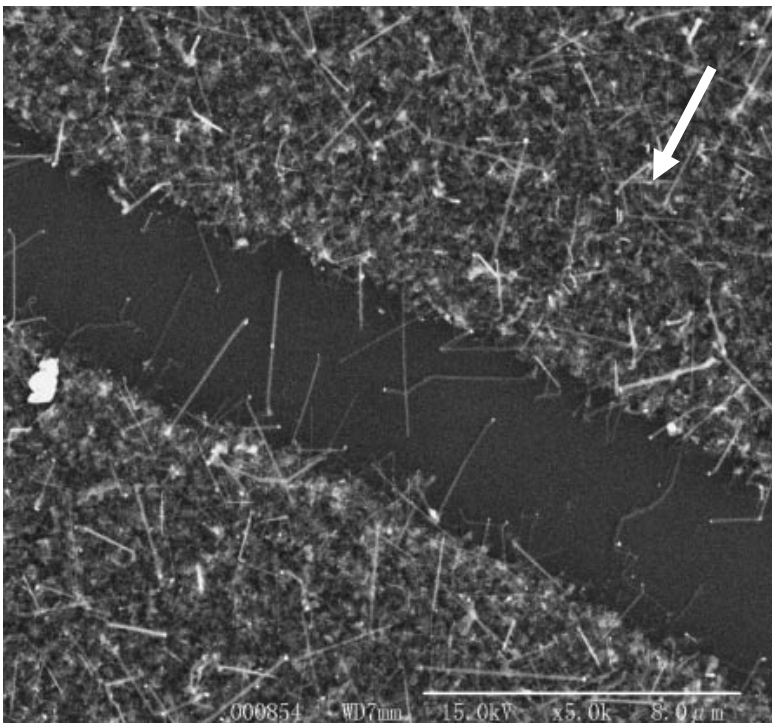

(a) Flow rate of $\mathrm{Ar}: 1.7 \mathrm{~cm}^{3} / \mathrm{s}$

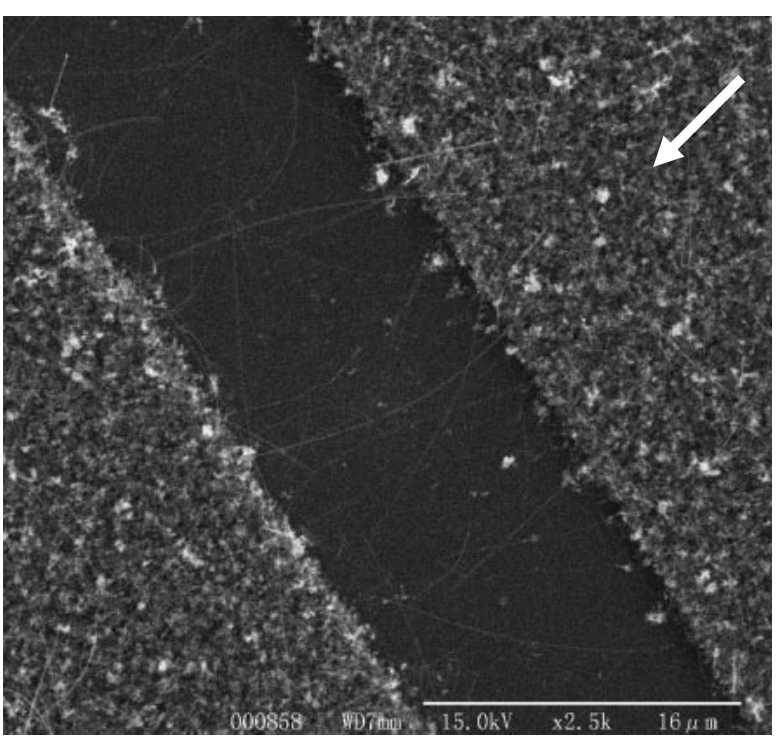

(b) Flow rate of Ar: $0.33 \mathrm{~cm}^{3} / \mathrm{s}$

Fig. 3 Argon flow rate dependence of $\mathrm{SiNW}$ growth at $573 \mathrm{~K}$ at a $\mathrm{Si}_{2} \mathrm{H}_{6}$ flow rate of $0.017 \mathrm{~cm}^{3} / \mathrm{s}$. The arrows indicate the gas flow directions.

described in the previous section. Figure 5 shows the result of the wiring experiment of silicon nanowires between gold dots. The wires were formed at $0.017 \mathrm{~cm}^{3} / \mathrm{s}$ of silane gas and $0.33 \mathrm{~cm}^{3} / \mathrm{s}$ of Ar gas at a total pressure of $0.67 \mathrm{kPa}$ at $569 \mathrm{~K}$. The distance between gold dots was set at $15 \mu \mathrm{m}$. The nanowires grew in various directions from one $3 \mu \mathrm{m}$-square gold dot. However, the growing direction of SiNWs tended to be along the gas flow direction as nanowires extended. Several nanowires finally reached other gold dots. When the distance between the dots was reduced, more complicated wiring occurred.

\section{Discussion}

\subsection{SiNW formation at low temperatures}

In the present study, silicon particles formed even at $423 \mathrm{~K}$, and silicon nanowires grew at temperatures lower than $523 \mathrm{~K}$.

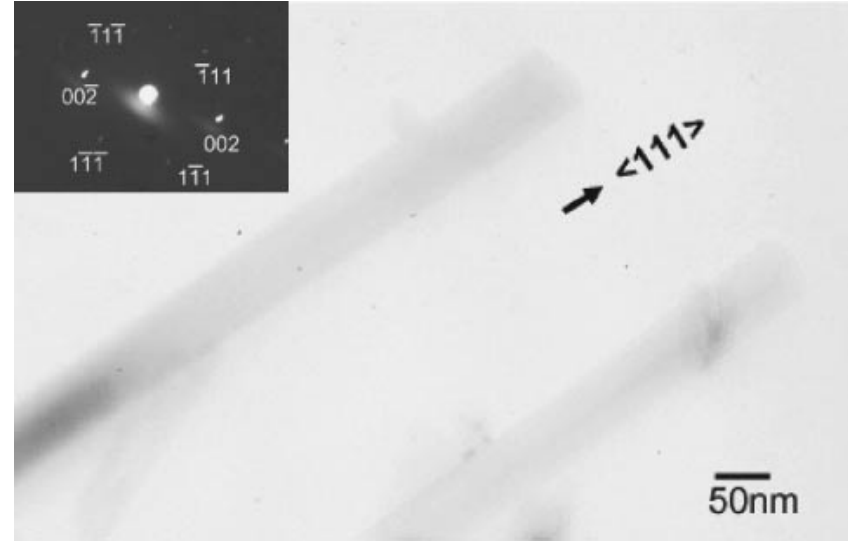

(a)

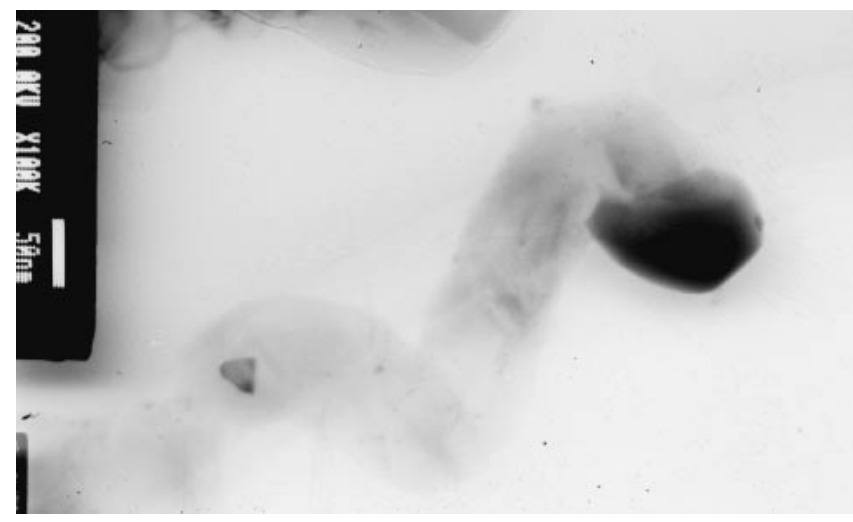

(b)

Fig. 4 TEM image of Si nanowires formed at $523 \mathrm{~K}$. Straight nanowire growing in the $\langle 111\rangle$ direction, (a); and gold particle on top of the nanowire, (b).

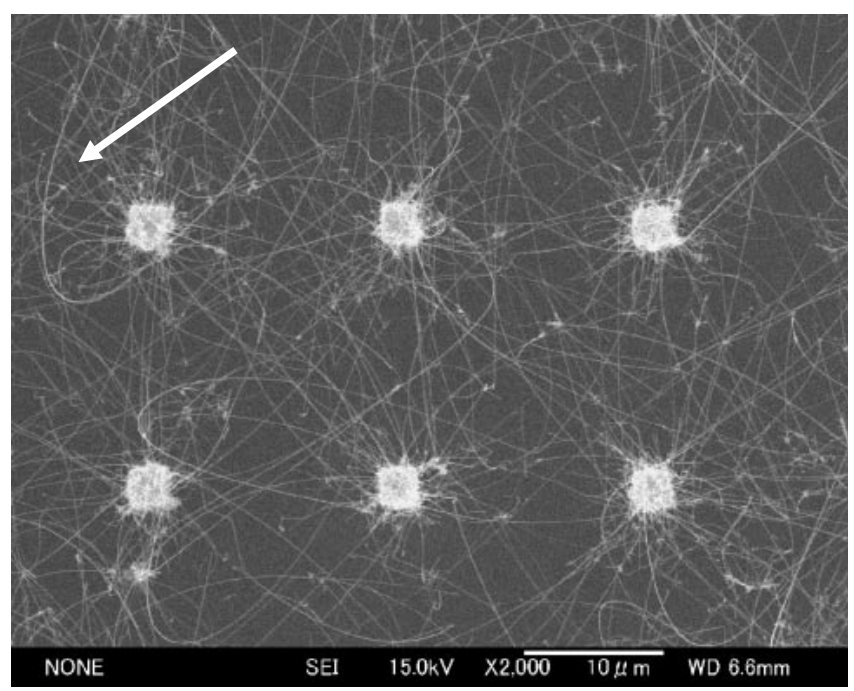

Fig. 5 Sel-wiring of SiNWs among gold dots. The arrow indicates the direction of the gas flow.

As is already reported, gold particles assist in the growth of SiNWs. ${ }^{20)}$ The growth of SiNWs is explained by the vaporliquid-solid (VLS) mechanism. Silane is decomposed to form a liquid $\mathrm{Au}-\mathrm{Si}$ eutectic on $\mathrm{Au}$ particles at low temperatures. ${ }^{21)}$ According to the phase diagram of $\mathrm{Au}-$ 
$\mathrm{Si}^{21)}$ the solubility of $\mathrm{Si}$ in solid Au is negligibly small. Pure silicon then precipitates at the liquid-solid interface. Since the eutectic temperature of $\mathrm{Au}-\mathrm{Si}$ is $636 \mathrm{~K}$, SiNWs can be formed at temperatures lower than the $\mathrm{Si}$ and $\mathrm{Au}$ melting points. The melting point of metals has been reported to decrease, both experimentally ${ }^{22)}$ and theoretically, ${ }^{23,24)}$ when the sizes of the metals are decreased. The surface energy at the liquid-solid interface contributes to the melting temperature of metal droplets. Considering that the liquid phase is thermodynamically equilibrated with the solid one, the lowering of the melting point, $\delta T$, with the size of the droplet is given by Takagi ${ }^{22)}$ as

$$
\delta T=2 \sigma \cdot T_{0} /(\rho \cdot L \cdot r),
$$

where $\sigma$ is the interfacial energy, $T_{0}$, the melting point of the bulk metal, $\rho$, the density of the metal, $L$, the latent heat of fusion, and $r$, the radius of the droplet. In the present case, solid silicon precipitates from the $\mathrm{Au}-\mathrm{Si}$ liquid phase. Assuming interfacial surface energy of $1.2 \mathrm{~J} / \mathrm{m}^{2}$ for the $\{111\}$ plane of silicon, ${ }^{25)}$ a latent heat of fusion of $59.38 \mathrm{~kJ} /$ $\mathrm{kg}$ for the eutectic, ${ }^{26)}$ and a $T_{0}$ of $636 \mathrm{~K}$, Eq. (1) is expressed as follows:

$$
\delta T \approx 1.4 \times 10^{3} / r(\mathrm{~nm}) .
$$

The $\delta T$ for the present case can be estimated to be 30 $140 \mathrm{~K}$ for $10-100 \mathrm{~nm}$. It is then likely that the melting point of the $\mathrm{Au}-\mathrm{Si}$ eutectic nanoparticles is reduced to around $473 \mathrm{~K}$.

In the present discussion, a simple model that assumes a small sphere of solid silicon that contacts the liquid phase is discussed. Since no interfacial energy data on a $\mathrm{Au} / \mathrm{Si}$ eutectic droplet have been reported, only the surface energy of solid silicon was used and assumed to be constant independently on the size of the droplet. For the growth of SiNWs from a $\mathrm{Au} / \mathrm{Si}$ droplet, the liquid-solid interfacial tension between the $\mathrm{Au} / \mathrm{Si}$ liquid and the solid silicon contacting the droplet, the surface tension of the $\mathrm{Au} / \mathrm{Si}$ droplet, and the surface tension of the solid silicon should be considered. ${ }^{27)}$ The surface energy of the small eutectic droplet depends on the physical properties, such as the vapor pressure and internal pressure of the droplet. ${ }^{23)}$ Further study, especially on the physical properties of nanosized liquid droplets and solids, will be needed to examine the SiNWs growth mechanism at low temperatures more precisely. As seen in Fig. 2(a), silicon deposited even at $423 \mathrm{~K}$. Silane gases are widely used by CVD and plasma CVD as sources to form silicon films. Several thermochemical data of $\mathrm{Si}_{2} \mathrm{H}_{6}$ have been reported. ${ }^{28,29)}$ The free energy, $\delta \mathrm{G}$, for the silicon formation reaction,

$$
\mathrm{Si}_{2} \mathrm{H}_{6} \rightarrow 2 \mathrm{Si}+3 \mathrm{H}_{2},
$$

can be estimated as $-142 \mathrm{~kJ} / \mathrm{mol}$ at $400 \mathrm{~K}$ and $-126 \mathrm{~kJ} / \mathrm{mol}$ at $298 \mathrm{~K}$. This result supports the idea that silicon decomposition from $\mathrm{Si}_{2} \mathrm{H}_{6}$ thermodynamically occurs at the present experimental temperatures even lower than $423 \mathrm{~K}$.

\subsection{Wiring of SiNWs}

As seen in Figs. 3 and 5, several silicon nanowire bridgings between gold dots were successful. The distance of approximately $15 \mu \mathrm{m}$ between dots was sufficient for wiring. However, silicon nanowires were radially produced from $3 \mu \mathrm{m}$-square gold dots and most nanowires extended in different directions against the gas flow direction. The growth direction of the SiNWs tended to be parallel to the gas flow direction with increasing the length, as shown in Fig. 3. However, the crystal growth direction was $\langle 111\rangle$ in the present experiment as indicated in Fig. 4. The same crystal growth direction of SiNWs was also observed in other experiments to form SiNWs using the thermal evaporation of Si powders. ${ }^{10,30)}$ These results indicate that the crystal growth direction of SiNWs should be considered and the wiring could not be controlled by the gas flow direction alone. Since one $3 \mu \mathrm{m}$-square dot on the substrate shown in Fig. 5 contains around 4000-10,000 gold particles, assuming a particle size of 10-50 nm, it will be necessary to reduce the size of the dots to limit the number of gold particles. Furthermore, it will be necessary for the silicon $\{111\}$ surface area size to correspond to one eutectic droplet size to fully control the growth direction of SiNWs. A finer lithography process will be required for the substrates.

\section{Conclusion}

SiNW formation at temperatures below $573 \mathrm{~K}$ and wiring between gold dots by SiNWs using disilane cracking reaction were attempted. The following conclusions were derived.

(1) Crystalline SiNWs with $10-100 \mathrm{~nm}$ in diameter were formed on a $\{100\}$ silicon wafer coated with a gold film even at $473 \mathrm{~K}$ using disilane. The typical crystal growth direction of the SiNWs was $\langle 111\rangle$.

(2) The nanowire thickness and length depended on the flow rate and pressure. Wires of several hundred $\mu \mathrm{m}$ long were formed at a low disilane flow rate of $0.33 \mathrm{~cm}^{3} / \mathrm{s}$ and a relatively high total pressure of $0.67 \mathrm{kPa}$. The growth direction of the SiNWs tended to be parallel to the flow direction of the reactant gas with increasing the length.

(3) The low-temperature formation of SiNWs was explained by lowering the melting point of the $\mathrm{Au}-\mathrm{Si}$ eutectic.

(4) Self-wiring by silicon nanowires between gold square dots placed $15 \mu \mathrm{m}$ from each other was successfully conducted.

\section{Acknowledgements}

This study was financially supported by the Budget for Nuclear Research of the Ministry of Education, Culture, Sports, Science, and Technology on the basis of screening and counselling by the Atomic Energy Commission.

\section{REFERENCES}

1) Y. Cui and C. M. Lieber: Science 291 (2001) 851-853.

2) S. Chung, J. Yu and J. R. Heath: Appl. Phys. Lett. 76 (2000) 20682070.

3) Y. Wu, J. Xiang, C. Yang, W. Lu and C. M. Lieber: Nature 430 (2004) 61-65.

4) C. A. Decker, R. Solanki, J. L. Freeouf, J. R. Carruthers and D. R. Evans: Appl. Phys. Lett. 84 (2004) 1389-1391.

5) J. D. Holmes, K. P. Johnston, R. C. Doty and B. A. Korgel: Science 287 
(2000) 1471-1473.

6) M. Lu, M. K. Li, L. B. Kong, X. Y. Guo and H. L. Li: Chem. Phys. Lett. 374 (2003) 542-547

7) E. W. Wong, P. E. Sheehan and C. M. Lieber: Science 277 (1997) 1971-1975.

8) A. M. Morales and C. M. Lieber: Science 279 (1998) 208-211.

9) Q. Gu, H. Dang, J. Cao, J. Zhao and S. Fan: Appl. Phys. Lett. 76 (2000) 3020-3021.

10) Q. Hu, G. Li, H. Suzuki, H. Araki and T. Noda: Jpn. J. Appl. Phys. 41 (2002) L7-L9.

11) J. Westwater, D. P. Gosain and S. Usui: Jpn. J. Appl. Phys. 36 (1997) 6204-6209.

12) Z. Q. Liu, W. Y. Zhou, L. F. Sun, D. S. Tang, X. P. Zou, Y. B. Li, C. Y. Wang, G. Wang and S. S. Xie: Chem. Phys. Lett. 341 (2001) 523-528.

13) L. Pan, K. Lew, J. M. Redwing and E. C. Dickey: J. Cryst. Growth 277 (2005) 428-436.

14) S. Hofmann, C. Ducati, R. J. Neill, S. Piscanec, A. C. Ferrari, J. Geng, R. E. Dunin-Borkowski and J. Robertson: J. Appl. Phys. 94 (2003) 6005-6012.

15) M. S. Islam, S. Sharma, T. I. Kamins and R. S. Williams: Nanotechnology 15 (2004) L5-L8.

16) X. Zhang, L. Zhang, G. Meng, G. Li, N. Jin-Phillipp and F. Phillipp: Adv. Mater. 13 (2001) 1238-1240.
17) B. Salhi, B. Grandidier and R. Boukherroub: J. Electroceram. 16 (2006) 15-21.

18) M. C. McAlpine, R. S. Friedman, S. Jin, K. Lin, W. U. Wang and C. M.Lieber: Nano Lett. 3 (2003) 1531-1535.

19) S. Bauerdick, A. Linden, C. Stampfer, T. Helbling and C. Hierold: J. Vac. Sci. Technol. B 24 (2006) 3144-3147.

20) R. S. Wagner and W. C. Ellis: Appl. Phys. Lett. 4 (1964) 89-90.

21) R. Castanet, R. Chastel and C. Bergman: Mater. Sci. Eng. 32 (1978) 93-98.

22) M. Takagi: J. Phys. Soc. Jpn. 9 (1954) 359-363.

23) J.-P. Borel: Surf. Sci. 106 (1981) 1-9.

24) F. Ercolessi, W. Andreoni and E. Tosatti: Phys. Rev. Lett. 66 (1991) 911-914.

25) R. J. Jaccodine: J. Electro. Chem. Soc. 110 (1963) 524-527.

26) H. S. Chen and D. Turnbull: J. Appl. Phys. 38 (1967) 3646-3650.

27) V. Schmidt, S. Senz and U. Goesele: Nano Lett. 5 (2005) 931-935.

28) H. K. Moffat, K. F. Jensen and R. W. Carr: J. Phys. Chem. 96 (1992) 7683-7695.

29) P. Ho, M. E. Coltrin, J. S. Binkley and C. F. Melius: J. Phys. Chem. 90 (1986) 3399-3406.

30) T. Noda, H. Suzuki, H. Araki, W. Yang, Y. Shi and M. Tosa: Appl. Surf. Sci. 241 (2005) 231-235 